\title{
Sentinel surveillance for patients with acute hepatitis in Egypt, 2001-04
}

M. Talaat, ${ }^{1}$ N. El-Sayed, ${ }^{2}$ A. Kandeel, ${ }^{2}$ M.A. Azab, ${ }^{1}$ S. Afifi, ${ }^{1}$ F.G. Youssef, ${ }^{1}$ T. Ismael, ${ }^{1}$ R. Hajjeh ${ }^{3}$ and F.J. Mahoney,3

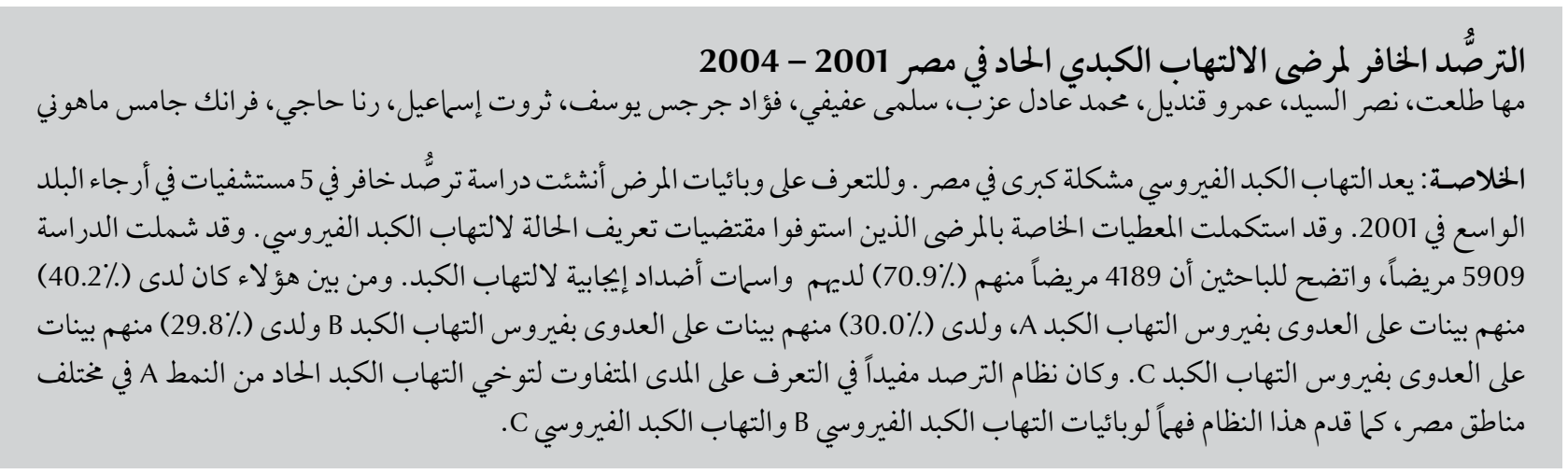

ABSTRACT Viral hepatitis is a major problem in Egypt. To define the epidemiology of the disease, sentinel surveillance was established in 5 hospitals in diverse areas of the country in 2001. Data were completed for patients meeting the case definition for viral hepatitis. Of a total of 5909 patients evaluated, 4189 (70.9\%) showed positive antibody markers for hepatitis. Out of those, $40.2 \%$ had evidence of hepatitis A virus (HAV) infection, $30.0 \%$ hepatitis B virus (HBV) and $29.8 \%$ hepatitis C virus (HCV) infection. This surveillance system was useful in identifying the variable endemicity of acute HAV infection in different regions and for better understanding the epidemiology of HBV and HCV infection.

\section{Surveillance sentinelle pour les patients atteints d'hépatite aiguë en Égypte, entre 2001 et 2004}

RÉSUMÉ L'hépatite virale est un problème majeur en Égypte. Afin de définir l'épidémiologie de la maladie, une surveillance sentinelle a été mise en place en 2001 dans cinq hôpitaux de différentes régions du pays. Les données ont été réunies pour les patients qui répondaient à la définition de l'hépatite virale. Sur 5909 patients évalués, 4189 (70,9 \%) étaient positifs aux marqueurs sérologiques de l'hépatite. Parmi ces derniers, 40,2\% d'entre eux étaient infectés par le virus de l'hépatite A, 30,0 \% par celui de I'hépatite B et 29,8\% par celui de l'hépatite C. Ce système de surveillance a démontré son utilité pour l'identification des variations de l'endémicité de l'infection aiguë par le virus de l'hépatite A dans différentes régions et pour une meilleure connaissance de l'épidémiologie de l'infection par les virus des hépatites B et C. 


\section{Introduction}

Viral hepatitis is a leading public health problem in Egypt and accounts for a substantial burden of disease and associated health care costs. Chronic liver disease due to hepatitis B (HBV) or hepatitis $\mathrm{C}$ virus infection ( $\mathrm{HCV}$ ) causes up to $7 \%$ of all deaths in Egypt annually, with $75 \%-85 \%$ of patients with chronic liver disease having HBV or HCV infection as a contributing cause [1].

Efforts to conduct laboratory-based surveillance for viral hepatitis are not generalized owing to limited laboratory capacity in many hospitals and the high costs of reagents. Data from the Egyptian Ministry of Health and Population (MOHP) indicates that approximately 20000 case reports are received annually from a network of 108 infectious disease hospitals. However, there are limitations in the interpretation of this data due to limited laboratory confirmation of disease, lack of a standardized case definition and inconsistency in reporting from the diverse reporting sources [unpublished MOHP reports].

Sentinel laboratory-based surveillance with standardized clinical and laboratory evaluation of patients is a helpful tool to better define the epidemiology of infectious diseases [2], particularly, in countries where the laboratory capacity is limited and costs are high. Such studies can be used to identify risk factors for disease and may assist in the development of a coherent prevention strategy. In addition, disease surveillance data is useful to evaluate the effectiveness of prevention strategies, monitor trends in disease occurrence, detect outbreaks and prevent secondary cases. This is of particular concern for Egypt, as widescale surveys conducted in the late 1990 s revealed that $10 \%-15 \%$ of the population were infected with $\mathrm{HCV}$, mostly older Egyptians who acquired their infections in the late 1970s and early 1980s during mass campaigns to treat schistosomiasis secondary to reusing syringes [3]. HCV infection is rarely diagnosed as acute hepatitis, except after contaminated blood transfusion [4]. In 2001 a sentinel surveillance system for viral hepatitis was established as an adjunct to these efforts to better define the epidemiology of the disease and to monitor the success of prevention activities.

The objectives of this study were to characterize the epidemiology of infectious agents causing acute viral hepatitis in Egypt, including HAV, HBV and $\mathrm{HCV}$, and to describe exposure related to transmission in a network of 5 infectious disease hospitals from 2001 to 2004.

\section{Methods}

\section{Study sites and structure}

Surveillance for hepatitis started in 5 infectious disease hospitals in diverse areas of the country in 2001. In most governorates in Egypt there is 1 infectious disease hospital where patients with acute viral hepatitis are referred for care. Hospitals participating in this sentinel surveillance network were selected by the MOHP to represent diverse regional ecologies that might influence hepatitis risk: Alexandria, Mahalla, Abassia, Qena and Aswan. Through this network, surveillance protocols were developed; and 1 surveillance coordinator was assigned in each sentinel site. The surveillance site coordinators were trained and were responsible for interviewing patients, handling logistical issues such as drawing blood, sending samples to the laboratory and completing data forms.

\section{Case-finding and data collection tools}

A suspected case of acute viral hepatitis was defined as any patient over 12 months old admitted to the infectious disease hospital with discrete onset of symptoms, a physician's diagnosis of jaundice (or elevated serum aminotransferase levels, if done), no other identified cause of jaundice and no evidence or history of chronic liver disease. Standardized clinical and laboratory evaluation was conducted for each patient meeting the case definition. Demographic data in the surveillance forms included age, sex, residence and history of exposure to well-recognized risk factors for bloodborne pathogen transmission, including transfusions, invasive medical procedures, percutaneous exposure to blood and injecting drug use.

\section{Laboratory procedures}

Approximately $3-5 \mathrm{~cm}^{3}$ of blood was sampled into red topped vaccutainers after obtaining informed consent from patients with acute jaundice syndrome. After collection, blood samples were kept at $4{ }^{\circ} \mathrm{C}$ until the serum separated from the clot. The vaccutainer tube was centrifuged for 10 minutes and the serum divided into aliquots in $2-3 \times 2 \mathrm{~cm}^{3}$ cryovials and stored at $-20^{\circ} \mathrm{C}$. Enzymelinked immunosorbent assay (ELISA) serology testing was performed locally at hospital laboratories. Sera were stored at $-20^{\circ} \mathrm{C}$ for further testing at reference laboratories. Laboratory focal points were trained to standardize ELISA techniques for diagnosis of viral hepatitis using commercially available kits according to manufacturer's instructions (Abbott Murex, Murex Biotech, United Kingdom). Approximately 2\% of samples tested were randomly selected for quality control retesting at a reference laboratory (USNaval Medical Research Unit, No.3).

\section{Clinical procedures and case definitions}

Staff training was conducted on case definitions, diagnosis, laboratory evaluation, treatment and counselling of patients with viral hepatitis. All patients were asked to provide informed consent. Patients who met the clinical case definition were classified as having 
laboratory-confirmed viral hepatitis based on the following results:

- Acute hepatitis A: +ve IgM antibody to hepatitis A virus (anti-HAV);

- Acutehepatitis B: +ve IgMantibody to hepatitis $B$ core antigen (anti-HBc);

- Hepatitis C: -ve IgM anti-HAV, -ve IgM anti-HBc, +ve antibody to hepatitis $\mathrm{C}$ virus (anti-HCV);

- Mixed hepatitis A hepatitis B: +ve IgM anti-HAV, +ve IgM anti-HBc.

\section{Results}

Between 1 January 2001 and 30 June 2004, a total of 5909 patients meeting the case definition of suspected acute viral hepatitis were evaluated in the participating institutions. Overall, 4189 (70.9\%) patients had positive serology for hepatitis markers. Out of these patients with laboratory-confirmed disease, 1684 (40.2\%) had evidence of HAV infection, 1256 (30.0\%) HBV infection and 1249 (29.8\%) HCV infection.

The median age for different types of hepatitis infection varied greatly. It was highest for HCV infection (45 years; interquartile range $36-53$ years) and lowest for patients with HAV infection (9

\begin{tabular}{|c|c|c|c|c|}
\hline Characteristic & $\begin{array}{c}\text { HAV } \\
(n=1684)\end{array}$ & $\begin{array}{c}\text { HBC } \\
(n=1256)\end{array}$ & $\begin{array}{c}\text { HCV } \\
(n=1249)\end{array}$ & $\begin{array}{c}\text { Non- } A \text {, non-C } \\
(n=1720)\end{array}$ \\
\hline \multicolumn{5}{|l|}{ Median age (years) } \\
\hline Rural & 4 & 25 & 42.5 & 23 \\
\hline Urban & 14 & 30 & 46 & 35 \\
\hline Total (i/quartile range) & $9(4-15)$ & $28(22-40)$ & $45(36-53)$ & $33(22-46)$ \\
\hline Males (\%) & 63 & 70 & 68 & 57 \\
\hline Urban (\%) & 54 & 76 & 88 & 84 \\
\hline Mortality (\%) & 0.1 & 0.4 & 0.2 & 0.2 \\
\hline
\end{tabular}

i/quartile = interquartile; $H A V=$ hepatitis $A$ virus; $H B V=$ hepatitis $B$ virus; $H C V=$ hepatitis $C$ virus. years; interquartile range $4-15$ years). The median age for patients with HBV infection (28 years) was slightly lower than the median age of patients without any serologic evidence of infection. There was a predominance of males for all types of infection, with a prevalence ranging from $57 \%$ for non- $A$, non-C to $70 \%$ for HBV infection. The majority of acute hepatitis cases were reported from urban areas (74\%). A low mortality rate was observed for all types of acute viral infections, which ranged between $0.1 \%$ and $0.4 \%$ (Table 1 ).

The etiology of viral hepatitis varied considerably by age (Figure 1). Among patients $<15$ years of age, $79 \%$ had evidence of HAV infection. Among patients $16-35$ years of age, $\mathrm{HBV}$ infection was the leading cause of disease. Overall, 21 persons born since the introduction of HBV vaccine into the expanded programme of immunization (EPI) were identified as being infected and 12 reported a history of $\mathrm{HBV}$ vaccination. HCV infection was most commonly reported among persons $>35$ years of age with a peak that occurred in the 46-50 years age group. Patients with non-A, non-Chepatitis occurred in all age groups, with a slight peak in cases counts in the age group $21-25$ years.

The proportion of pathogens as a cause of viral hepatitis varied substantially among participating hospitals, particularly for HAV, where the proportion

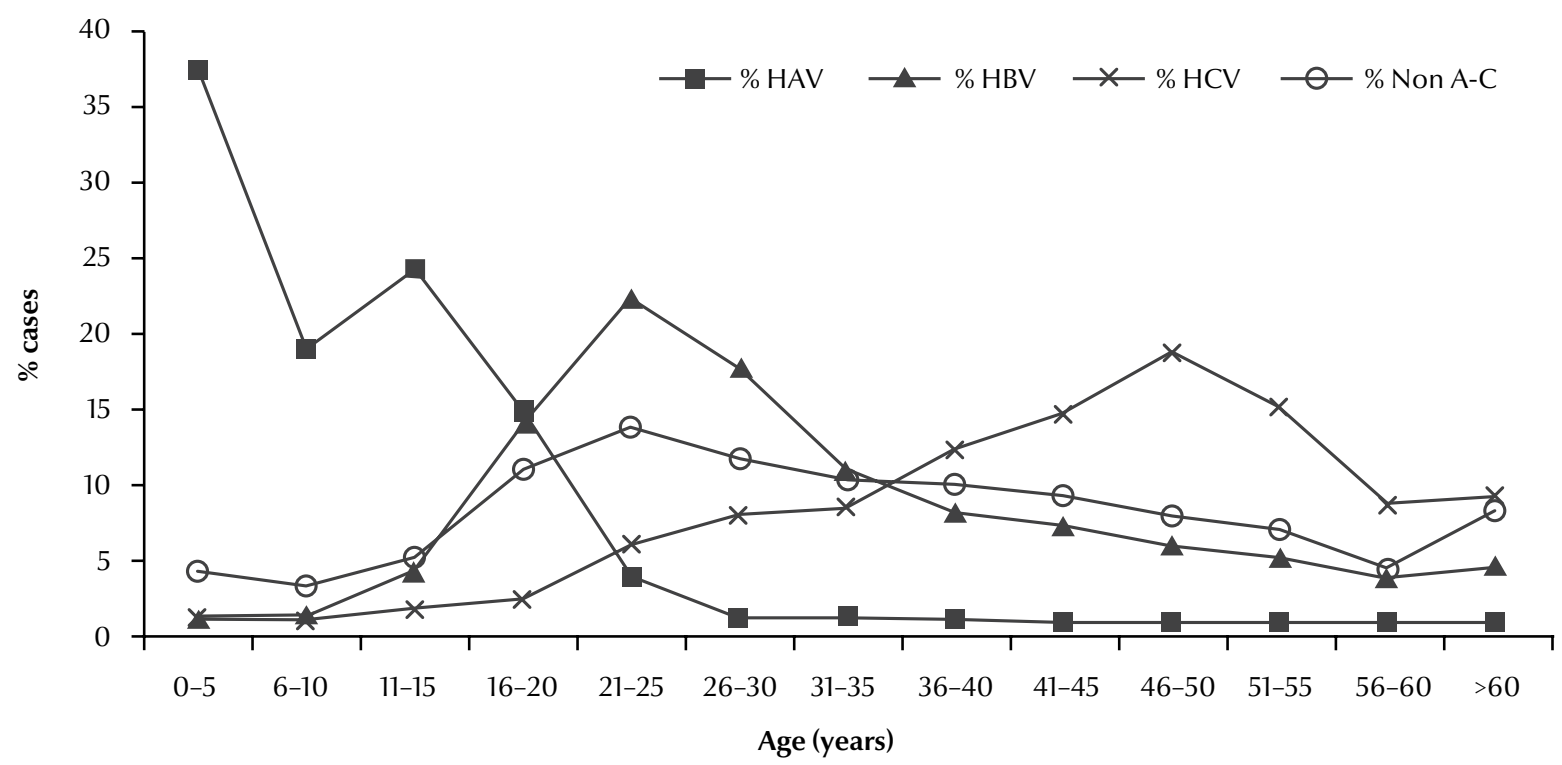

Figure 1 Age distribution of acute viral hepatitis cases recorded at hepatitis sentinel surveillance hospitals, Egypt, January 2001 to June 2004 


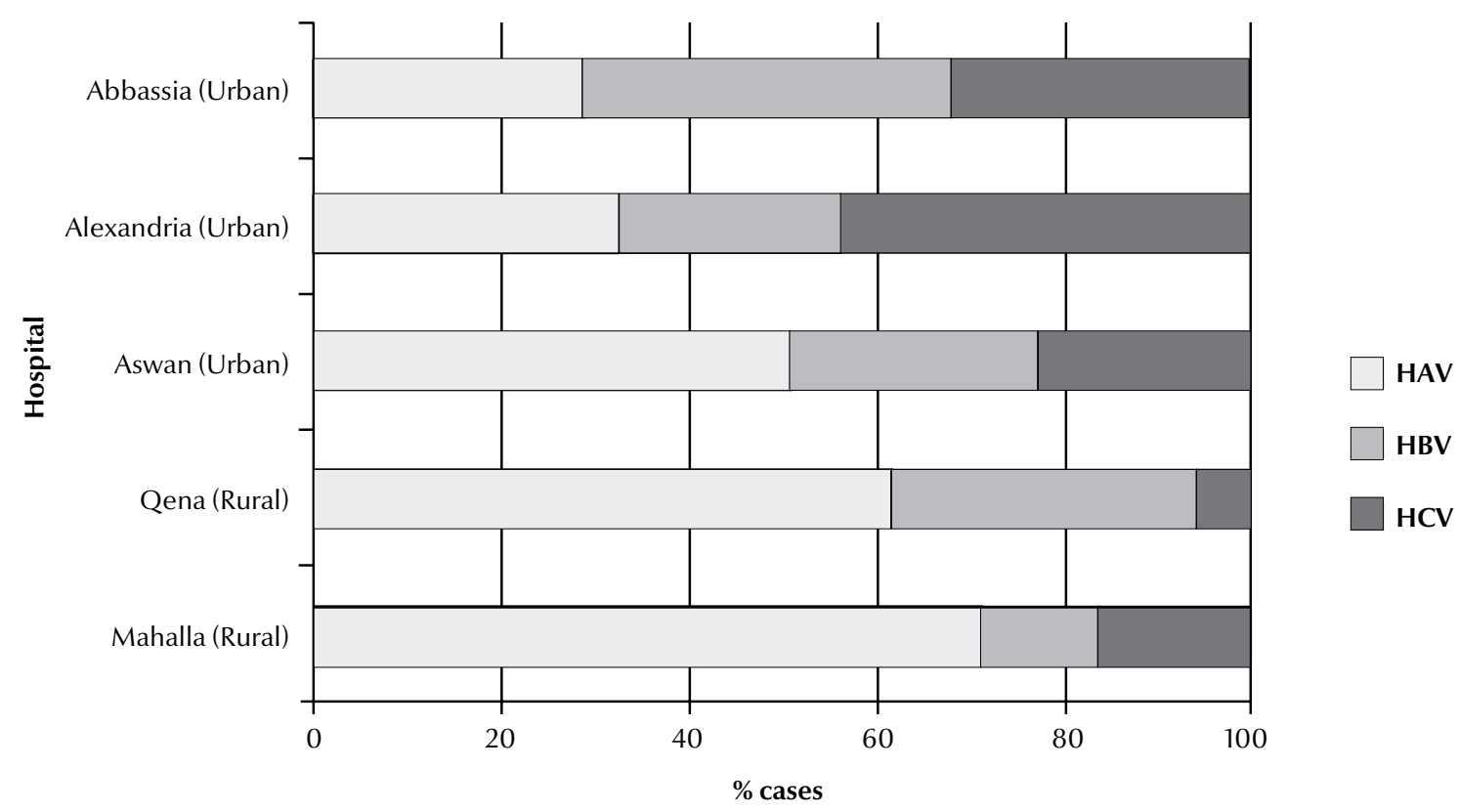

Figure 2 Distribution of cases of acute viral hepatitis recorded at the 5 hepatitis sentinel surveillance hospitals, Egypt, January 2001 to June 2004

was greater in hospitals located in rural governorates (Mahalla and Qena) compared to hospitals located in urban areas (Abbassia, Alexandria and Aswan) (Figure2).HAV patients were identified throughout the year with a peak in late summer. There was a biphasic peak in the number of non-A, non-C patients in the spring and early summer (Figure 3 ).

Data on potential exposures associated with blood-borne pathogen transmission were recorded for all patients. Generally, the frequency of these exposures was greater among patients with $\mathrm{HBV}$ and $\mathrm{HCV}$ infection compared to patients with HAV infection (Table 2). The most frequently reported exposure among patients with

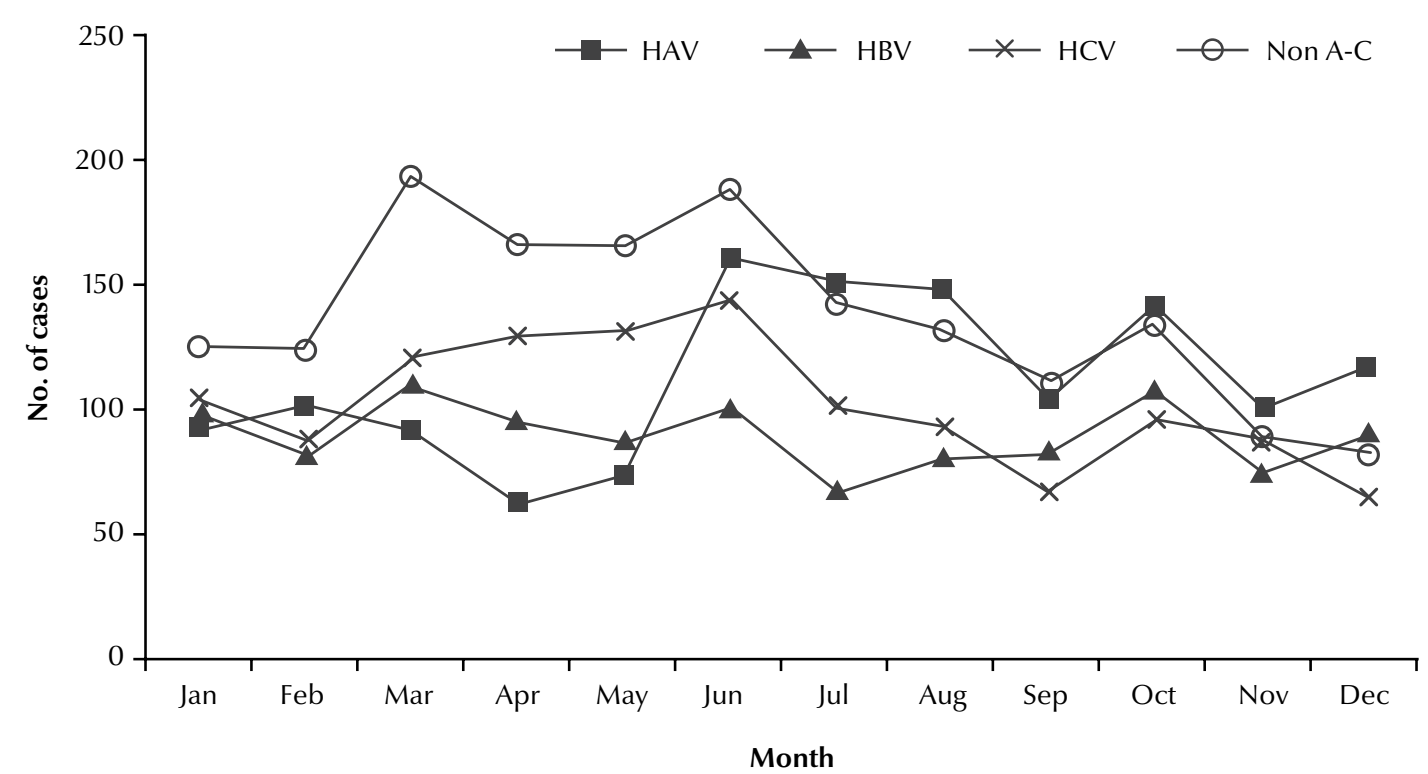

Figure 3 Monthly distribution of acute viral hepatitis cases (cumulative) at 4 hepatitis sentinel surveillance sites, Egypt, January 2001 to June 2004 (Qena was excluded as surveillance started in 2002) 


\begin{tabular}{|c|c|c|c|c|c|c|c|c|}
\hline \multirow[t]{2}{*}{ Exposure } & \multicolumn{2}{|c|}{$\begin{array}{c}\text { HAV } \\
(n=1684)\end{array}$} & \multicolumn{2}{|c|}{$\begin{array}{c}\text { HBV } \\
(n=1256)\end{array}$} & \multicolumn{2}{|c|}{$\begin{array}{c}\text { HCV } \\
(n=1249)\end{array}$} & \multicolumn{2}{|c|}{$\begin{array}{l}\text { Non-A-C } \\
(n=1720)\end{array}$} \\
\hline & No. & $\%$ & No. & $\%$ & No. & $\%$ & No. & $\%$ \\
\hline Blood transfusion & 12 & 1 & 51 & 4 & 100 & 8 & 57 & 4 \\
\hline IV drug user & 23 & 1 & 135 & 11 & 91 & 8 & 93 & 6 \\
\hline $\begin{array}{l}\text { IV drug user (age-adjusted } \\
20-40 \text { years) }\end{array}$ & 10 & 1 & 103 & 8 & 44 & 4 & 58 & 3 \\
\hline Dental procedure & 97 & 6 & 151 & 12 & 158 & 13 & 188 & 12 \\
\hline Injection & 278 & 17 & 352 & 29 & 442 & 35 & 519 & 30 \\
\hline Percutaneous procedure & 27 & 2 & 94 & 8 & 95 & 8 & 139 & 9 \\
\hline Surgical procedures & 42 & 3 & 132 & 11 & 183 & 15 & 217 & 14 \\
\hline Needlestick injury & 65 & 4 & 230 & 19 & 130 & 11 & 224 & 14 \\
\hline $\begin{array}{l}\text { Contact with other hepatitis } \\
\text { patients }\end{array}$ & 69 & 4 & 46 & 4 & 25 & 2 & 35 & 2 \\
\hline
\end{tabular}

$H A V=$ hepatitis $A$ virus; $H B V=$ hepatitis $B$ virus; $H C V=$ hepatitis $C$ virus; $I V=$ intravenous.

HBV infection was receipt of an injection within the past 6 months, which was reported by $29 \%$ of patients. Other common exposures among patients with HBV infection included needlestick injuries, invasive medical procedures and a history of injecting drug use. Similar frequencies for these exposures were also noted for patients with HCV infection (Table 2). In addition, patients with HCV infection were more likely to report a history of blood transfusion.

\section{Discussion}

The treatment of patients with viral hepatitis is generally supportive, and diagnostic testing is of limited value in clinical management. However, identification of the etiology of disease is important to provide appropriate counselling for long-term follow-up, particularly for patients with HCV and $\mathrm{HBV}$ infection. It is difficult to provide testing in Egypt given the high number of patients with jaundice and the cost of reagents. Viral hepatitis is highly endemic in rural and urban Egypt, and patients are traditionally referred to infectious disease hospitals for care. The majority of patients are diagnosed based on clinical criteria and epidemiological information, without laboratory confirmation of disease. The MOHP does not support laboratory-based surveillance through the public hospital laboratories, where hospitals have limited resources to support diagnostic testing. Thus, the value of routine surveillance data without laboratory confirmation of disease is limited. Similarly, the usefulness of laboratory-based sentinel surveillance in Egyptian hospitals is also a subject of considerable debate. Hospital-based surveillance is biased, as it does not reflect the overall burden of disease and it does not capture mild and moderate hepatitis cases. However, it does describe the spectrum of disease among hospitalized patients and the results of our study identified several useful aspects of sentinel surveillance for viral hepatitis in Egypt.

This study showed that HAV infections are prevalent in rural areas in Egypt, and infections occur early in life (median age 4 years). The age-specific pattern for HAV in the study showed a high infection rate (88\%) with HAV among children under 5 years $[5,6]$. This is in contrast to urban areas where infection occurred later in life (median 14 years). The implications of this epidemiological shift are important because the severity of clinical disease increases among older age groups. Since the age of infection with HAV increases when countries move towards urbanization and from high to intermediate endemicity levels $[7,8]$, Egypt may express a similar shift over the next decade leading to higher morbidity rates among older age groups.

$\mathrm{HCV}$ infection is highly endemic in Egypt, with seroprevalence rates of 10\%-20\% among blood donors [9], and even higher rates reported among segments of the general population $[3,5,10-13]$. The age distribution of patients with $\mathrm{HCV}$ in this study (median age 45 years) suggests that infections are occurring among older age groups, who are more likely to be exposed to invasive procedures in the health care setting. This is also the age group with the highest prevalence of HCV infection $[10,14]$ and community-based studies suggest these age cohorts continue to experience high incidence of disease [personal communication]. The frequency of health care exposures and age distribution of disease suggest that exposures associated with health care are a likely source of HCV infection in Egypt.

Most studies describing risk factors associated with transmission of $\mathrm{HCV}$ in Egypt suggest that hospitalization and invasive procedures are the main risk factors for disease [10,11]. A high percentage of patients with $\mathrm{HCV}$ and HBV reported a history of receiving injections, suggesting that unsafe injections may be an important risk factor for bloodborne pathogen transmission in Egypt. A recent survey to measure injection frequency in several communities in Upper and Lower Egypt described a high individual-based prevalence of injections (26\%) over a 3-month period, with about $20 \%-40 \%$ of injections provided by the informal sector [15]. Other possible sources of blood-borne pathogen exposures included surgical and dental procedures, which were reported in $15 \%$ of patients with HCV and $11 \%$ 
with HBV during the 6 months prior to hospitalization. However, in-depth epidemiological studies are needed to better characterize this association.

The frequency of health care exposures was also high among patients with $\mathrm{HBV}$ infection. However, the group was in an age range (18-35 years) that does not often seek health care services. In particular, the predominance among young adult males suggests that other exposures such as injecting drug use and sexual practices may play a role in $\mathrm{HBV}$ transmission.

A key value of infectious disease surveillance systems is to evaluate the impact of prevention programmes, particularly for vaccine-preventable diseases. Because HBV infections among children are usually asymptomatic, surveillance data is of limited value in demonstrating disease reduction, and evaluation of programme impact requires a different approach. A key goal of $\mathrm{HBV}$ immunization programmes is to reduce the prevalence of hepatitis B surface antigen ( $\mathrm{HBsAg}$ ) among cohorts born since programme implementation, and vaccination programme managers often use periodic serosurveys to demonstrate a reduction in the prevalence of HBsAg. Prior to the introduction of $\mathrm{HBV}$ vaccine into the EPI in 1992, HBV was considered moderately endemic in Egypt with 4\% of the population having evidence of chronic HBV infection $(\mathrm{HBsAg}+\mathrm{ve})[16,17]$. There have been no serosurveys among children born since the introduction of the vaccine in Egypt; however, the findings of acute disease transmission in these cohorts indicate there is ongoing HBV transmission and more in-depth evaluation of the immunization programme is needed.

One of the important implications of this sentinel surveillance system is the high percentage of patients with negative serology for any hepatitis markers (non-A, non-C) who presented with clinical symptoms of acute viral disease (jaundice and fever). More investigations have to be done for these patients as they might be infected with other infections, such as leptospirosis, ricketsiosis or others. Even a percentage of these patients might be infected with acute HCV, where no clear test is available to diagnose these patients.

The introduction of laboratorybased sentinel surveillance for viral hepatitis has provided limited, but valuable, information on the public health importance of the various forms of viral hepatitis, including the number of hospitalized patients for each disease over time, the geographic distribution of disease, and the identification of its possible risk factors. Yet laboratory-based testing has provided a platform to identify and confirm outbreaks. Although this system is of limited value to monitor control measures, it could be useful over time if the surveillance is maintained and efforts are initiated to prevent disease transmission. This effort should be complemented by in-depth epidemiological studies among patients with acute disease to better identify exposures associated with disease transmission. Such studies are ongoing, and it is anticipated that the identification of risk factors will help guide prevention efforts and public health policies to prevent viral hepatitis in these communities.

\section{Acknowledgements}

The authors acknowledge with sincere thanks and appreciation the outstanding support provided by the staff working in the infectious disease hospitals.

This work was supported by USAID Work Unit no. 80000.000.000.E0022.

The views expressed in this article are those of the authors and do not necessarily reflect the official policy or position of the Department of the Navy, Department of Defense, the US Government, or the Egyptian Ministry of Health and Population.

The study protocol was approved by the Naval Medical Research Unit No. 3 Institutional Review Board in compliance with all applicable Federal regulations governing the protection of human subjects.

\section{Copyright statement}

This article fits the description stipulated by the new US Copyright Act of a "United States Government work". The authors are employees of the U.S. Government and this work was prepared as part of their official duties. Title 17 USC 105 provides that "Copyright protection under this title is not available for any work of the United States Government work as a work prepared by a military service member or employee of the United States Government as part of that person's official duties".

\section{References}

1. Yates SC et al. Hepatocellular carcinoma in Egyptians with and without a history of hepatitis B virus infection: association with hepatitis C virus (HCV) infection but not with (HCV) RNA level. American journal of tropical medicine and hygiene, 1999, 60:714-20.

2. Afifi $\mathrm{S}$ et al. Hospital-based surveillance for acute febrile illness in Egypt: a focus on community-acquired bloodstream infec- tions. American journal of tropical medicine and hygiene, 2005, 73:392-9.

3. Frank $\mathrm{C}$ et al. The role of parenteral antischistosomiais therapy in the spread of hepatitis C virus in Egypt. Lancet, 2000, 355:887-91.

4. Di Bisceglie AM. Hepatitis C. Lancet, 1998, 351:351-5 
5. Fix AD et al. Prevalence of antibodies to hepatitis $\mathrm{E}$ in two rural Egyptian communities. American journal of tropical medicine and hygiene, 2000, 62(4):519-23.

6. Meky FA et al. Active surveillance for acute viral hepatitis in rural villages in the Nile delta. Clinical infectious diseases, 2006 , 42:628-33

7. Margolis HS, Shapiro CN. Considerations for the development of recommendations for the use of hepatitis A vaccine. Journal of hepatology, 1993, 18(Suppl. I2):S56-60.

8. Fiore AE. Hepatitis A transmitted by food. Clinical infectious disease (food safety), 2004, 38.

9. Arthur RR et al. Hepatitis $\mathrm{C}$ antibody prevalence in blood donors in different governorates in Egypt. Transactions of the Royal Society of Tropical Medicine and Hygiene, 1997, 91:271-4.

10. Medhat A et al. Hepatitis $\mathrm{C}$ in a community in Upper Egypt: risk factors for infection. American journal of tropical medicine and hygiene, 2002, 66:633-8.

11. Habib $M$ et al. Hepatitis $C$ virus infection in a community in the Nile Delta: risk factors for seropositivity. Hepatology, 2001, 33:248-53.
12. Mohamed MK et al. Viral hepatitis C infection among Egyptians. The magnitude of the problem: epidemiological and laboratory approach. Journal of the Egyptian Public Health Association, 1996, 71(1-2):79-111.

13. El-Zayadi AR et al. Prevalence of GBV C/hepatitis G virus viraemia among blood donors, health care personnel, chronic non- $\mathrm{B}$ non- $\mathrm{C}$ hepatitis, chronic hepatitis $\mathrm{C}$ and hemodialysis patients in Egypt. Journal of virological methods, 1999, 80:53-8.

14. Abdel Aziz F et al. Hepatitis C virus (HCV) infection in a community in the Nile delta: population description and HCV prevalence. Hepatology, 2000, 32:111-5.

15. Talaat $\mathrm{M}$ et al. Overview of injection practices in two governorates in Egypt. Tropical medicine and international health, 2003, 8:234-41.

16. Qirbi N, Hall AJ. Epidemiology of hepatitis B virus infection in the Middle East. Eastern Mediterranean health journal, 2001, 7:1034-45.

17. Kamal M, Aoun S. Natural history of hepatitis C: factors contributing to the evolution and outcome of infection. Cairo, Ministry of Health and Population, 1999.

\section{Hepatitis - water-related infection}

Hepatitis has a number of infectious and non-infectious causes. Among the infectious causes, hepatitis A and hepatitis E are associated with inadequate water supplies and poor sanitation and hygiene. Both these infections are found worldwide, particularly in countries with poor sanitary and hygienic conditions. Countries with economies in transition and some regions of industrialized countries where sanitary conditions are sub-standard are also highly affected.

International norms ("guidelines") on water, sanitation and hygiene, including guidelines for drinking-water quality, safe use of wastewater, safe management of health care wastes and safe recreational water environments can be accessed from:

http://www.who.int/entity/water_sanitation_health/norms/en/index.html 